\title{
Supporting Information to the paper entitled Guiding Function and Basis Function Optimization in Correlation Function Quantum Monte Carlo Calculations of Vibrational Excited States in Molecules
}

\author{
Frederico V. Prudente ${ }^{1 *}$, Luis S. Costa ${ }^{2 \dagger}$ and Paulo H. Acioli ${ }^{2 \ddagger}$ \\ ${ }^{1}$ Instituto de Física, Universidade Federal da Bahia \\ Campus Universitário de Ondina, 40210-340, Salvador, Bahia, Brazil \\ ${ }^{2}$ Instituto de Física, Universidade de Brasilia \\ CP 04455, 70919-970, Brasília, DF, Brazil
}

*e-mail: prudente@ufba.br

†e-mail: luis@fis.unb.br

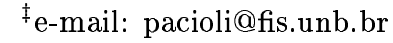




\begin{tabular}{|c|c|c|}
\hline \multirow{9}{*}{ 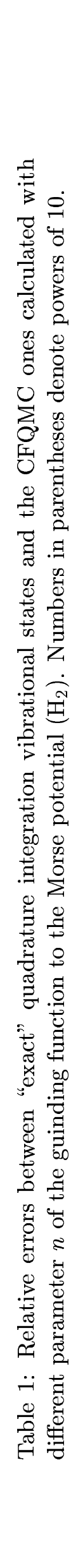 } & 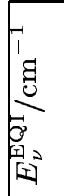 & 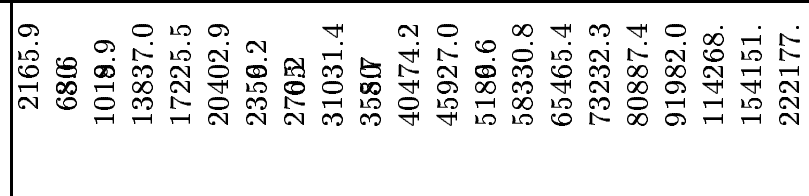 \\
\hline & & 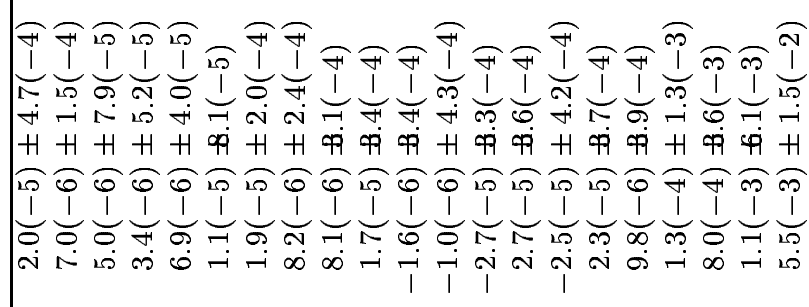 \\
\hline & & 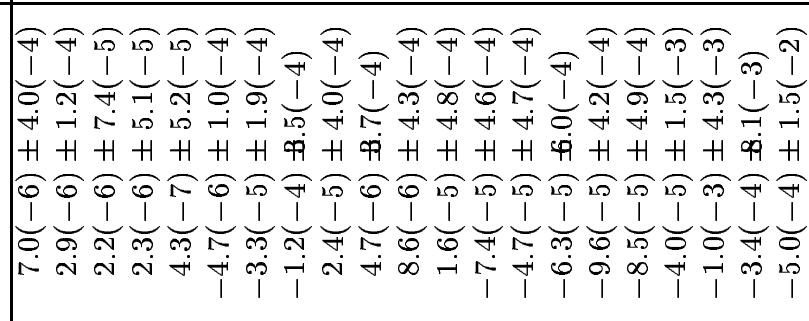 \\
\hline & & 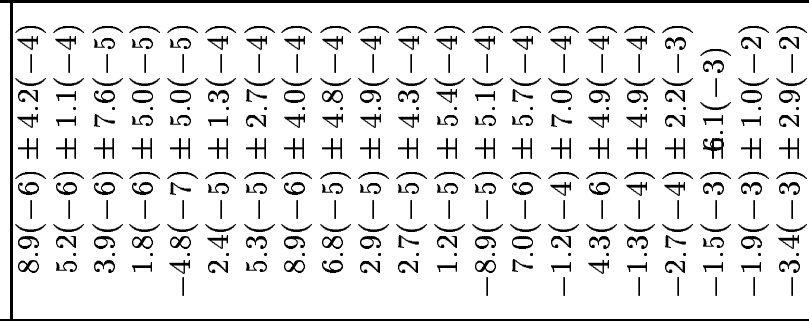 \\
\hline & 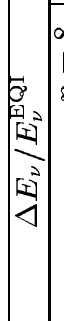 & 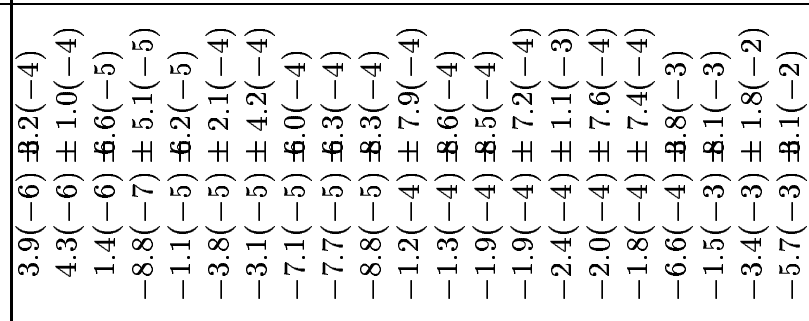 \\
\hline & & 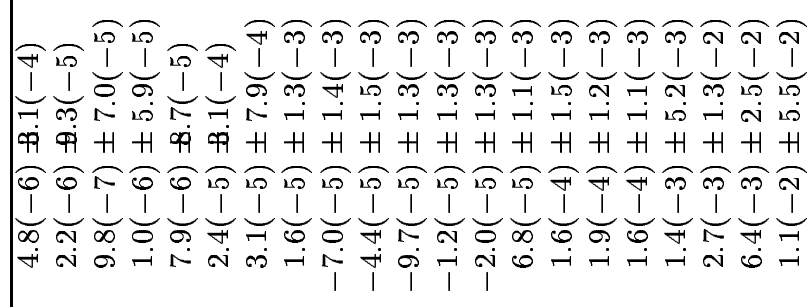 \\
\hline & & 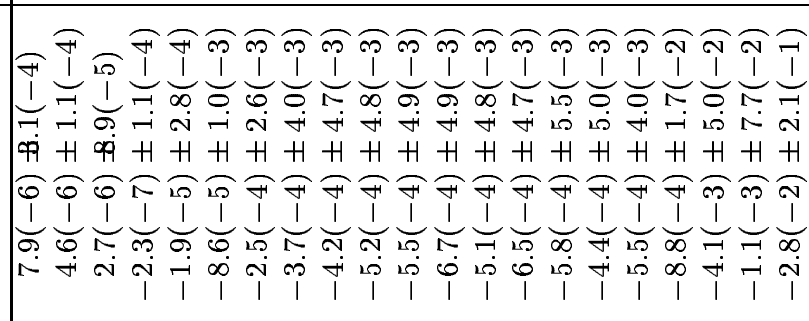 \\
\hline & & 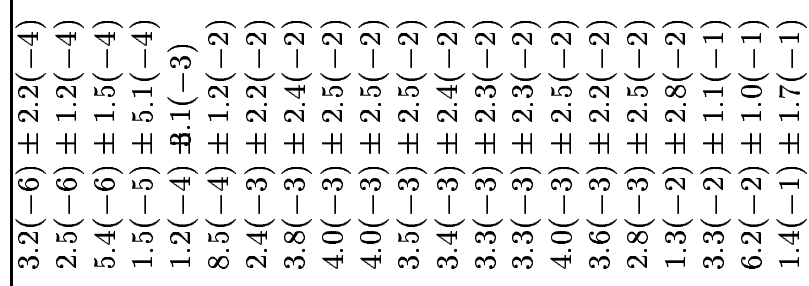 \\
\hline & $\lambda$ & $\Rightarrow 100$ N \\
\hline
\end{tabular}




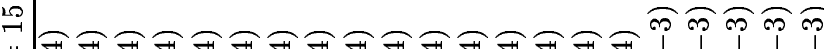

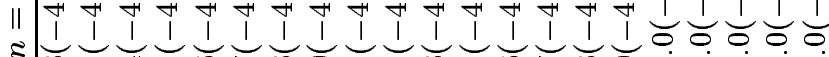

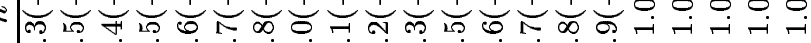

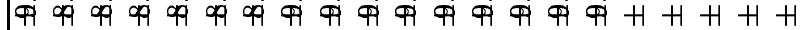

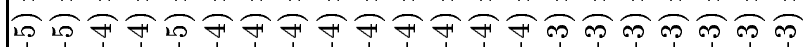

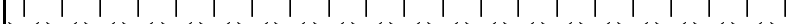

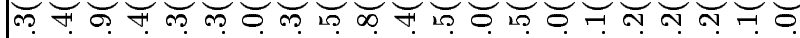
a) a

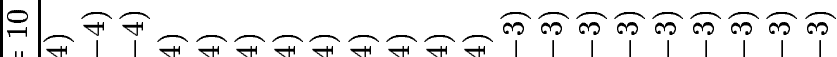

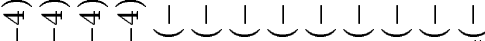

\&

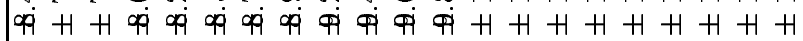

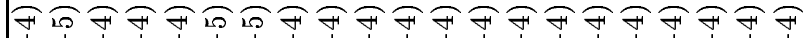

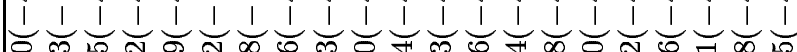
m ti ti a n m $-7-r-1$

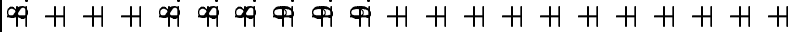

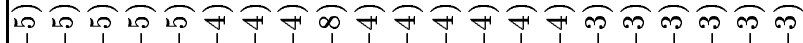

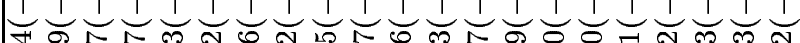
मं

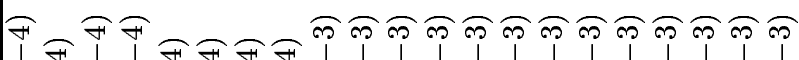
\&

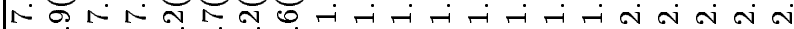

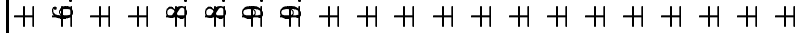

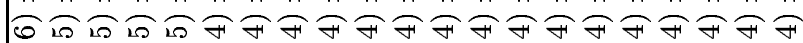

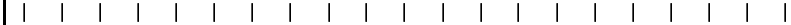
๓

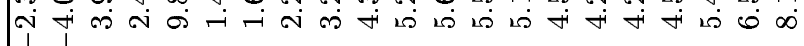

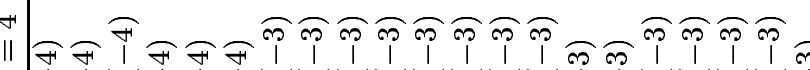

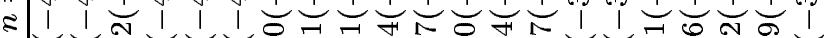

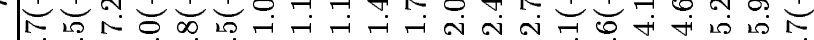

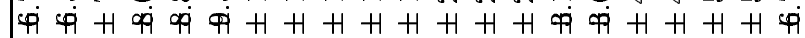

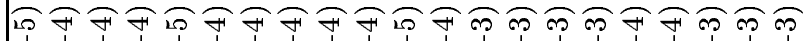
I I I I I I I I I I I I I I I I I I I I I I I I I I I I I I I I I I ֻ

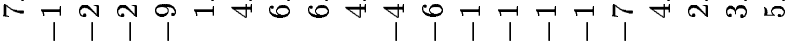

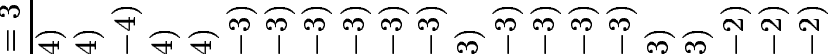

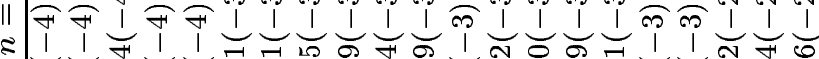
-

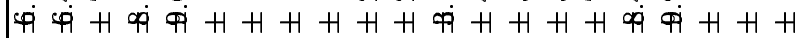

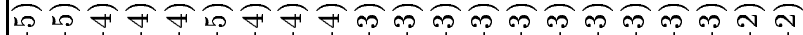

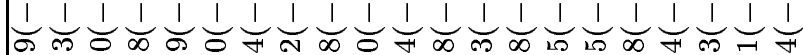
म $\infty$ मा m

- 